\title{
Do Job Coach Effective to PWDs Secured a Job in Malaysia
}

\author{
Noor Fatihah Mat Radzi' ${ }^{1}$, Abd Halim Ahmad ${ }^{2}$ \\ ${ }^{1,2}$ Universiti Utara Malaysia \\ Ifatihahmatradzi@gmail.com \\ ²abdhalim@uum.edu.my
}

\begin{tabular}{ll}
\hline ARTICLEDETAILS \\
\hline History & \\
Received & $:$ February \\
RevisedFormat & $:$ March \\
Accepted $\quad:$ April \\
\hline
\end{tabular}

Keywords :

job coach, effective, PWDs

\begin{abstract}
S
The right to work has been recognized through article 23(1) of the Universal Declaration of Human Rights 1948. But, opportunity and participation of persons with disabilities (PWDs) in the workforce is still a challenge in Malaysian context. Various efforts and initiatives have been continuously undertaken to secure inclusion of PWDs in the workforce. Malaysia introduced Supported Employment (SE) through Job Coach programme largely provided by the Department of Social Welfare and other Non-Governmental Organisations (NGOs) focuses on helping PWDs in securing employment in the workplace. This conceptual paper discuss about the effetiveness Job Coach to PWDs enhancing participation in the open job market. Implications of the study to the organisation in particular and to the general public at large are also examined and to be considered in order to ensure PWDs inclusion in the workplace and their well-being could be continuously and effectively promoted.
\end{abstract}

C2020 STIM Lasharan Jaya Makassar

\section{INTRODUCTION}

In the Malaysian population, PWDs can be considered one of the most vulnerable minorities. According to the WHO, $7 \%$ of the world's population is disabled and about $2 \%$ will require some form of rehabilitation service. PWDs are defined as those who have physical, mental or emotional deficits in the long run, interacting with various barriers that may limit their full and effective participation in society (Disability Act 2008). Previously, PWDs were often portrayed with negative views.

To ensure that the disabled continue to develop and contribute to the country, the Department of Social Welfare (JKM) in collaboration with Japan International Cooperation Agency (JICA) has launched a Project to Support Participation of Persons With Disabilities, which is Job Coach. The Job Coach Service Program has been identified as a job support system to help the PWDs out of work. Since 1986 in the United States (US), the PWDs have been assisted in gaining employment through this program.

According to statistics, in 1986, 9,000 PWDs has benefited from this program and increased to 140,000 PWDs in 1995, while centers providing these services increased to 3,600 centers in 1995 compared to 300 in 1986 . Recognizing the success achieved in the US, Japan has been following in the footsteps and has been gaining traction among the disabled. In this regard, the JICA introduced this Job Coach program in Malaysia to help PWDs find employment through phases that include before, during and after employment. The table below shows the Malaysian Key Performance Indicator (MKPI) prediction within states in 2019. 
Table 1

\begin{tabular}{|c|c|c|c|}
\hline \multicolumn{4}{|c|}{ MKPI PREDICTION WITHIN STATES (2019) } \\
\hline NO. & STATE & TARGET & ACHIEVE \\
\hline 1. & Perlis & 3 & 9 \\
\hline 2. & Kedah & 10 & 23 \\
\hline 3. & Pulau Pinang & 15 & 33 \\
\hline 4. & Perak & 10 & 14 \\
\hline 5. & Kuala Lumpur & 20 & 12 \\
\hline 6. & Selangor & 20 & 21 \\
\hline 7. & Melaka & 15 & 8 \\
\hline 8. & Negeri Sembilan & 20 & 0 \\
\hline 9. & Johor & 15 & 7 \\
\hline 10. & Pahang & 15 & 6 \\
\hline 11. & Terengganu & 10 & 7 \\
\hline 12. & Kelantan & 15 & 34 \\
\hline 13. & Sabah & 15 & 11 \\
\hline 14. & Sarawak & 15 & 0 \\
\hline 15. & Labuan & 2 & 0 \\
\hline TOTAL & & 200 & 185 \\
\hline
\end{tabular}

Source : (Department of Social Welfare Statistic Report (2019)

Job Coach is not just a coach who trains the PWDs, but the Job Coach acts as a bridge or intermediary to connect the PWDs and the employer throughout the job process. Job Coach play a role in assisting the PWDs and employers in adapting to the work environment and workplace, and taking into account the ability of the PWDs to work in a comfortable and productive environment. In addition, the role of Job Coach is to create a mutually beneficial relationship between employees with employers and colleagues, so that they can help the PWDs continue working while improving the quality of service.

Through the support of Job Coach, PWDs will not only have the opportunity to work, but most importantly to stay in the job. As of December 2018, a total of 185 PWDs received benefits through the Job Coach Services Program (JKM, 2018). The company or employer that employs the PWDs also increases. The role of Job Coach is also to help the PWDs to create a conducive working environment. PWDs can apply for Job Coach service through the District Public Welfare Office, PDK or the Voluntary Welfare Organization (NGO) at their residence. Therefore, SE through the Job Coach program is implemented to provide suitable jobs for the PWDs based on their skills and abilities.

\section{Table 2}

\begin{tabular}{ccc}
\hline PWDs & WORKING WITH JOB COACH SUPPORT & (DECEMBER 2018) \\
\hline NO. & CATEGORY & TOTAL \\
\hline $\mathbf{1 .}$ & Learning Disability & 132 \\
$\mathbf{2 .}$ & Physical Disability & 21 \\
$\mathbf{3 .}$ & Mental Disorder & 4 \\
$\mathbf{4}$. & Hearing Problem & 12 \\
\hline $\mathbf{5 .}$ & Speech Problem & 0 \\
\hline $\mathbf{6 .}$ & Vision Problem & 7 \\
\hline $\mathbf{7 .}$ & Various Disablity & 9 \\
\hline
\end{tabular}

Source : (Department of Social Welfare Statistic Report (2019) 


\section{PROBLEM STATEMENT}

Employment is one of the key elements of a country's development towards socio-economic development, and even one of the criteria for a developed country to achieve high income status. The first problem to be addressed in this research is that the employment issue for PWDs. The freedom of speech by individuals and non-governmental organizations (NGOs) in presenting opinions and concerns about the PWDs in developed countries has been gaining international attention. However, discrimination against the PWDs in the workplace has led to a stereotype view of PWDs workers or those applying for employment among them (Draper, Reid \& McMahon, 2010). The issue of job opportunities and the various barriers faced by the PWDs make it difficult for them to compete in the job market until they are forced to rely on their families and the government (Aizan Sofia \& Jamiah, 2015; Lau, Ahmad Shamsuri \& Peng, 2011).

According to Wolffe (2012), work-related issues can have a negative impact on the PWDs. For example, the lack of job opportunities will lead to the unemployment crisis among the PWDs until their become worst (McDonnall, 2005). In addition, it can also affect the wellbeing of the family, create negative self-concept and create job dissatisfaction among the PWDs (Peter \& Ferlis, 2014; Mellisa, Yen \& See, 2011; Wong, 2017). This is will negatively affect the future aspirations of the future generation of PWDs (Lau, Ahmad Shamsuri \& Chew, 2011).

PWDs in Asia generally have less job opportunities (NST, 2005). In Malaysia, PWDs in the public sector are still down which is 0.24 percent compared to one percent of PWDs according to their respective policies (Berita Harian, 2017). Factors that cause PWDs in Malaysia to not be considered in open job market because of their lack of education and skills (Ang, 2014). There is evidence that most employers are less proactive in hiring PWDs and have stereotyped views of PWDs in the workplace (Lengnick-Hall et al., 2008).

Ju Zhang and Pacha's (2011) study showed that lack of employability skills was a major factor that prevented the PWDs from gaining a place in the open job market. Employability skills according to Sheppard \& Unsworth (2010), refer to general competencies required to perform certain types and levels of work such as communication skills, problem solving skills, teamwork skills and interpersonal skills of an individual. Weakness in mastery of these skills will lower one's chances for employment.

Many researchers have also shown that PWDs are often portrayed with negative views (Barnes, 1992; Jayasooria et al, 1997; Gouvier et al, 2003; Brown et al, 2009). They have been treated like second class people and some people are still questioning their capabilities and efforts. This can be seen when there is still prejudice towards the PWDs (Reid \& Bray, 1998; Wilson, 2003). However, they need jobs and benefits from employment just like ordinary people. Studies have also found that there is a lack of job opportunities for them to work in the mainstream due to their intellectual shortage, social stigma against them, and lack of education and training provided (Burge et al, 2007; Migliore et al, 2008; Yeo, 2007).

Although various campaigns, programs, and ongoing job training are given to PWDs, most employers still feel that they are not entitled to employment simply because of the disadvantage of the organization, while in reality most of them have recognized qualifications for entry into an industry. In fact, employers are also found to employ the PWDs to work within the organization solely to fulfill corporate social responsibility (CSR) solely to enhance the image of the organization (Dibben, 2002).

This study is motivated by the fact that Malaysia in process of eradicating discrimination against to the PWDs (Ta \& Leng, 2013) to implement equal opportunities in the open job market. Malaysia has received guidelines from the Biwako Millennium Framework (BMF) and the United Nations (UN) in Convention on the Rights of the Disabled in developing policies to support the PWDs in equal opportunities. The community in particular employers need to change their attitude by focusing on the capabilities of the PWDs rather than their 
own inability to help the PWDs in Malaysia to have a job. Therefore, more needs to be done to provide the PWDs with the opportunity to participate fully in the field of employment.

This study was supported by Brown et al, (2006) and Wehman (2006) who reported that most PWDs usually work in protected workshops under the Social Welfare Department or stay at home. The increasing number of PWDs has led to the problem of unemployment for these people. Implementation of the SE through the Job Coach programme is an effort to fulfill the responsibility of placing the PWDs in current work, especially in open employment. However, the implementation of tis programme through the Government Opportunities program and cooperation from JICA has not been extensive (Wan Arnidawati, 2013). In-depth research can be done by looking at PWDs and employment issues through the effectiveness of the Job Coach program in open employment and implementing SE through the Job Coach programme.

\section{Purpose of Inquiry and Inquiry Questions}

This conceptual paper is intended to identify and understand the effectiveness of Job Coach Implementation on PWDs in Malaysia. Therefore, the inquiry questions for this paper are:

1. Do Job Coach Effective PWDs secured a job?

2. Does the Job Coach help PWDs to reduce unemployment?

The answer to the inquiry questions will be based on an extended review and analysis of literature.

\section{Significance of the Inquiry}

This conceptual paper is significant because it will explore whether the implementation of Job Coach to ensure PWDs inclusion in the workplace and their well-being could be continuously and effectively promoted. This paper also make recommendations for future research.

\section{LITERATURE REVIEW}

Previous and contemporary studies on employers perspectives with PWDs are still inconsistent (Ju et al., 2013; Lengnick-Hall, Gaunt, \& Kulkarni, 2008). Even though a number of studies indicated that PWDs are productive, reliable, hardworking loyal and have positive characters (Norani, Khalid and Nor Aishah (2001; Waxman, 2017; Annuar Aswan, Mohd Faizal \& Abdul Razak, 2017), the reality shows that this group of people is not getting equal employment opportunities. Norani, Khalid and Nor Aishah (2001) also argued that PWDs have many hidden potentials and resources where they should be given job opportunity and training in order to fully integrate them in the society at large.

These conflicting views are contributed by several reasons such as evolving and challenging current working environment and economic conditions, implementation of legislative laws and policies which made the employers fear of inappropriate actions and consequences towards disabled employees, and employers still have inadequate information about PWDs (Ju, Zhang, \& Pacha, 2012; Kaye et al., 2011; Khoo et al., 2012). The ongoing misconceptions among employers have made the issue remain tricky and intricate to deal with (Araten-Bergman, 2016; Lengnick-Hall, Gaunt, \& Kulkarni, 2008; Luecking, 2008; Scotch \& McConnel, 2017). Waxman (2017) suggests that certain stereotypes and myths about employees with disabilities still permeate the business environment and effects corporate behavior in respect to PWDs. Moreover, Heron and Murray (2003) also argued that negative attitudes, often linked to discrimination; unequal access to education and training; inaccessible buildings, lack of accessible information; inaccessible transportation; lack of assistive devices and support services, low self- esteem and over protective families, lack of supportive legal environment, and lack of policy support were the obstacles faced by PWDs. 
As previously discussed, Job Coach programme is one of the measures initiated by the government of Malaysia to assist PWDs equal and effective participation in the work force. The role of a job coach is providing continuous support to both PWDs and employers with the aim of stable employment (Ogawa et al., 2012). As attested by previous research work and studies, PWDs need some kind of basic support before and during employment process. It will help the PWDs to be independent and enable to do special task that assigned to them.

The Job Coach programme also have succeeded in changing employers perceptions of PWDs who are often labeled as less competitive. Job Coach is an innovative program for the PWDs to get a job and help them learn and perform job tasks as well as interpersonal skills necessary to be accepted as workers and to enable them stay on their employment. Job Coach also help employers and other employees in understanding disabilities and the needs of disabled employees.

Several authors argued that the participation of Job Coach are regarded as crucial in preparing PWDs for employment (Ogawa et al., 2012; Pathmanathan, 2014). The implementation of Job Coach programme has shown significant improvement in retaining PWDs in work place and will be considered as an important tool in the process of social inclusion for PWDs in Malaysia (Pathmanathan, 2014). In brief, it is an impactful intervention used to address typical work related issues of PWDs. Job Coach tender their service delivery to maximize the use of employer, co- worker, community and family supports to enable individual PWDs to obtain, learn and maintain a job. In this respect, supports provided by Job Coach include client assessment, job development, job placement, job site training and on-going follow along services (Parent \& Unger, 1994).

Since the Job Coach program was implemented in Malaysia in 2012, it has also succeeded in transforming a more open and competitive work environment among the PWDs. As of December 2015, a total of 1,868 participants involving 431 PWDs, 241 employers, and 108 trainers attended the training involving government, private and non-governmental organizations (NGOs). The implementation of the Job Coach opens the eyes of many large companies in the country to take on the PWDs while providing access to these groups. Successful programs that have been practiced in developed countries such as the US, Europe and Japan have encouraged JKM to establish Job Coach Network Malaysia (JCNM) as a mechanism for promoting permanent employment among the PWDs. JCNM serves as an entity responsible for ensuring the continuity of the Job Coach program by preparing action plans for 2016-2018. JKM has also provided trainers expertise for ASEAN Training Coaches.

Most researchers have provided empirical findings since thia programme was implemented to a greater extent in some countries. In Malaysia, the Job Coach studies are relatively small, compared to the US, European countries and Japan (Wan Arnidawati, 2013). Therefore, it is important to understand as much as possible about the development and effectiveness of Job Coach in Malaysia.

In discussing low participation of PWDs, most studies as exemplified by preceding discussions, focus on perceptions from employers, experiences of PWDs themselves, and from perspectives of family members, but there are limited studies particularly in Malaysia capturing views from Job Coach who themselves directly have contacts or involved in helping the disabled to secure employment. Given all the challenges and obstacles of PWDs participation in the work force and primary role of Job Coach in supporting PWDs and employers, it is crucial to ascertain the dynamics and complex factors of this phenomenon. These Job Coach have dealt with PWDs themselves, PWDs families, the employers as well as various organisations, and become familiarized with the real issues facing PWDs in the job market. With that note, the role of Job Coach is critical in addressing three critical issues of unemployment, poverty and inequality that confronting PWDs in Malaysia. 
Although SE through Job Coach programme has been found to be an effective way of helping PWDs in their work environment, several criticisms have been found (Bond, Drake, \& Becker, 2008). This is because, while excluding PWDs from participating in this programme, individuals need to have a competitive job as a goal and be willing to work to be effective. Another critique of this programme is, although the programme is found to be effective in securing employment, the duration of employment offered is only temporary (Bond, Drake, \& Becker, 2008). However, to see this programme over a long period of time, further studies are needed.

Thus, the discussion of previous studies clearly indicates that this programme has a positive effect on PWDs, despite some criticisms. However, previous researchers have also shown that interest was more in the perspective of the PWDs experience and focused on learning disabilities only. More in-depth research can be done by looking at the effectiveness of Job Coach on PWDs by understanding the complex problems faced by PWDs in open employment. In general, many studies have been conducted by researchers regarding this programme that involve the disabled.

\section{METHODS FOR COLLECTING AND ANALYZING LITERATURE}

This conceptual paper is based solely on a review and analysis of research and data from the literature. Several methods were used to collect and analyze the literature. First, research was conducted using the Google search engine. Terms such as 'Job Coach', 'SE' and 'employment for PWDs' were used, and a limited amount of information was found. Second, research on three databases pertaining to social work and sociology were examined. The databases were SocIndex, JSTOR Sociology, and Social Work Abstracts. The articles were retrieved and reviewed. Other terms were searched and sorted in the same manner. Third, books on the topic for this conceptual paper were searched. The same terms used in the database search was used to find books related to the topic. Two books were deemed useful and were borrowed from the library for further reading. Fourth, psychology databases were reviewed to obtain insight on perceptions and how people come to make perceptions in general. Also, a dissertation database, for social sciences, was explored in order to gain insight on how to prepare a scholarly paper.

\section{Data Collection and Data Sources for Future Research}

This is a conceptual paper that is based solely on a review of literature on the topic of employment and PWDs. For future research a quantitative study would be conducted to obtain data on the PWDs perception of Job Coach. A quantitative method would be used because the research question would be a casual one ("Do Job Coach Effective to PWDs Secured a Job"). The procedures for conducting research would be to create a valid instrument that measures perceptions toward PWDs. That survey has been validated, and if it could be obtained, would be a good instrument for a future study. The sample would consist of person's who have had some type of experience with the PWDs. The participants will also be informed that participation in the survey is completely confidential and voluntary and they are free to leave at any time.

\section{Data Analysis Strategies for Future Research}

The results discussed are significant despite the number of respondents were relatively small. Perhaps, in the future, it may be worth investigating perspectives and experiences of Job Coaches in other related organizations views might be obtained. Further study should also be conducted using mix methods in order to capture broader and more insightful data. In brief, while there are some limitations associated with the approach used here and given the nature of this action study, the results of this research provide meaningful findings that should be of interest to both researchers and practitioners across nations especially in Malaysian context. 


\section{FINDINGS FROM LITERATURE}

Literature was useful for understanding the topic for this conceptual paper. The literature enabled me to answer the two inquiry questions.

\section{INQUIRY QUESTION 1:}

Do Job Coach Effective to PWDs Secured a Job?

\section{FINDING 1:}

Previous studies have found that SE through the Job Coach programme is a more effective and successful approach than traditional rehabilition or shelted programme (Bond et al, 2001). Drake et al (1999) study compared this programme with traditional rehabilition programme. This study examines three hypotheses namely; Job Coach will result in higher employment rates, higher wages, and more time off work compared to the traditional rehabilition programme. While traditional rehabilition programme are seen as less competitive in their jobs as they only work in protected workshops. Similarly, a study by Lehman et al (2002), who also compared SE through Job Coach programme with traditional rehabilition programme. This programme is focused on the job search process and ongoing support while working. While traditional rehabilitation services provide a wide range of services, including skills training and job placement opportunities. The results show that this programme is more experienced in competitive jobs than traditional rehabilition programme.

Those who are associated with Job Coach achieve a more competitive job, higher income, and do not show a level of stress (Cook et al., 2005). The results of this programme implementation also have a positive impact on those who are homeless and involved in substance abuse problems (Rosenheck \& Mares, 2007), as well as those living in the interior (Drake, McHugo, Bebout, Becker, Harris, et al., 1999 ).

\section{INQUIRY QUESTION 2:}

Does the Job Coach help PWDs to reduce unemployment?

\section{FINDING}

Based on literature it is clear that the Job Coach helps PWDs to reduce unemployment. Although PWDs are placed at a less skilled level through this programme (Bond et al., 1997), at least they are not excluded from the careers life. A study by Keel, Mesibov, and Woods (1997) found that Job Coach had a positive effect on people PWDs find a competitive job and integrated with a retention rate of $89 \%$. This study is supported by Burns et al. (2007), who stated that those who participated in this programme were expected to find jobs and individuals with previous work experience had better job retention rates. Hillier et al. (2007) also conducted a study on this programme over a 2 years period in individuals between 18 and 36 years old. The results were quite remarkable in that participants kept their jobs for more than a year. In addition, there was an increase in the income of those who joined by over $400 \%$. Employers give high ratings to staff who participate in this programme and show that the process is a positive experience. Furthermore, disabled workers themselves report high levels of satisfaction with their work.

\section{RECOMMENDATIONS FOR FUTURE RESEARCH}

Based on the literature the following recommendations for future research are

below: 
Recommendation 1: Further research should be conducted to test whether experience PWDs towards Job Coach.

Recommendation 2: Further research should be conducted to employer who hired the PWDs to work.

\section{CONCLUSION}

The findings led me to draw conclusions about the effectiveness Job Coach to PWDs secured a Job and make recommendations for future research. It is obvious that Job Coach is able to train the PWDs to become skilled workers in certain fields. The PWDs can increase their productivity and become skilled with the help of their Job Coach. PWDs will also have the courage to do something out of the ordinary when it comes to getting a job. In order to gain acceptance of public assistance, policy makers must access all the impact perceptions about PWDs and Job Coach, one of them is Media. Media is able to influence opinions by presenting information in a manner that will get the PWDs or public to think a certain way towards a topic.

\section{REFERENCE}

Ahmad Shamsuri Muhamad, Lau, P.L., \& Chew, F.P.(2011). Peranan Kaunselor dan Perkhidmatan Kaunseling Kerjaya Bagi Orang Kurang Upaya. Jurnal ATIKAN, 1, (2), 233-245. (Non-ISI/Non-SCOPUS).

Aizan Sofia, A., \& Jamiah M. (2015). Geography, poverty and Malaysia disabled women. GEOGRAFIA Online Malaysia Journal of Society and Space, 11(7), $82-91$

Annuar, A., Isa, M. F. A., Manaf A. R. A. (2017). Employees with disabilities:

Malaysian employers' reflections. International Journal of Academic Research, Business \& Social Sciences, 7(12), 270-283.

Ang, M. C. H. (2014). Do persons with disabilities act ( 2008 ) and organisational culture influence managerial intention to hire persons with disabilities?: The Malaysian perspective. Jurnal Pengurusan, 41, 81-89

Araten-Bergman, T. (2016). Managers' hiring intentions and the actual hiring of qualified workers with disabilities. The International Journal of Human Resource Management, 1-21

Barnes, C. (1991). Disabled People in British and Discrimination: A Case for AntiDiscrimination Legislation. London: Hurst \& Co

Berita Harian, (2017): Jumlah OKU di sektor awam bawah sasaran. Access November 1, 2019 http://www.bhplus.com.my/node/277607

Bond, G. R., Drake, R. E., Muesser, K. T., \& Becker, D. R. (1997). An update on supported employment for people with severe mental illness. Psychiatric Services, 48(3):335-346.

Brown, L., Shiraga, B., \& Kessler, K. (2006). The quest for ordinary lives: the integrated post-school vocational functioning of 50 workers with significant disabilities. Research and Practice for Persons with Severe Disabilities, 31(2): 93121.

Burge, P., Ouellette-Kuntz, H., \& Lysaght, R. (2007). Public views on employment of people with intellectual disabilities. Journal of Vocational Rehabilitation. 26: 29-37

Drake, R. E., Becker, D. R., Biesanz, J. C., Torrey, W. C., McHugo, G. J., \& Wyzik,. P. F. (1994). Rehabilitative day treatment vs. supported employment: vocational outcomes. Community Mental Health Journal, 30(5): 519-532

Heron, R. \& Murray, B. (2003). Assisting disabled persons in finding employment: A practical guide. 2nd edition. International Labour Organization: Bangkok

Jayasooria, D., Krishnan, B., \& Ooi, G. (1997). Disabled people in a newly industrialising economy: Opportunities and challenges in Malaysia. Disability \& Society, 12, 455-463.

Ju, S., Zhang, D. \& Pacha, J. (2011). Employability Skills Valued by Employers as 
Important for Entry-Level Employees With and Without Disabilities. Career Development for Exceptional Individuals.

Lengnick-Hall, M.L, Gaunt, P.M, Kulkarni, M. (2008). Overlooked and underutilized: People with disabilities are an untapped human resource. Human Resource Management, 47(2), 255-273. http://doi.org/10.1002/hrm

Luecking, R. G. (2008). Emerging employer views of people with disabilities and the future of job development. Journal of Vocational Rehabilitation, 29(1), 3-13.

McMahon, B.T., Hurley, J.E., West S.L., Chan F., Roessler, R., Rumrill, P.D., Jr. (2008). A comparison of EEOC closures involving hiring versus other prevalent discrimination under the Americans with Disabilities Act. Journal of Occupational Rehabilitation, 18, 106-111

Migliore, A., Grossi, T., Mank, D., \& Rogan, P. M. (2008). Why do adults with intellectual disabilities work in sheltered workshops? Journal of Vocational Rehabilitation, 28(1): 29-40.

Norani Mohd Salleh, Khalid Abdullah \& Nor Aishah Buang. (2001). Job opportunities for special needs population in Malaysia. Jurnal Pendidikan, 27, 7785.

Ogawa, H., Sakai, D., Swee Lan, Y. \& Kuno, K. (2012). Introduction To Job Coach: Promoting Sustainable Employment Of Persons With Disabilities. Kuala Lumpur: MPH Group Publishing.

Pathmanathan, R.N. (2014). Social inclusion for persons with disabilities in Malaysia through supported employment: An untroduction to job coach programme. Conference Proceedings: International Social Development Conference, pp 368372. Pusat Pengajian Pemabngunan Sosial, Universiti Utara Malaysia: Sintok Kedah

Parent, W. \& Unger, D. (1994). The role of the job coach: Orchestrating community and workplace support. American Rehabilitation, 20(3), 2-12.

Peter, V., \& Ferlis, B. (2014). Cabaran pekerjaan dan kesan kepada kesejahteraan hidup OKU penglihatan yang berkeluarga di Sabah. Seminar Kebangsaan Integriti Keluarga 2014.

Reid, P. M., \& Bray, A. (1998). Real Jobs: The perspectives of workers with learning difficulties. Disability \& Society, 13(2): 229-239.

Scotch, R. K. \& McConnel, C. E. (2017). Disability and the future of work: A speculative essay. pp. 249-266 in Barbara M. Altman (Ed) (2017). Factors in studying employment for persons with disability: How the picture can change. United Kingdom: Emerald Publishing

Ta, T. L., \& Leng, K. S. (2013). Challenges faced by Malaysians with disabilities in the world of employment, disability. CBR, 24(1), 6-21.

Wan Arnidawati (2013). Supported Employment: Persons with Learning Difficulties in Malaysia. University of Warwick.

Wehman, P. (2006). Integrated employment : If not now, when? If not us, who? Research and practice for Persons with Severe Disabilities, 31(2): 122-126.

Wilson, A. (2003). "Real Jobs", "Learning Difficulties" and Supported Employment. Disability \& Society, 18(2): 99-115.

Wolffe, K.E. 2012. Career counseling for people with disabilities: A practical guide to finding employment $\left(2^{\text {nd }}\right.$ ed.)

Yeo, S. L. (2007). Self-advocacy Movement of Persons with Learning Disabilities: A Case Study in the Malaysian Context. Kuala Lumpur: University of Malaya 